\title{
Solidification of Selected Al-Ru-Y Samples
}

\author{
L.A. Cornish, ${ }^{*}$ and M.J. Witcomb** \\ * Physical Metallurgy Division, Mintek, Private Bag X3015, Randburg 2125, South Africa \\ ** Electron Microscope Unit, University of the Witwatersrand, Private Bag 3, WITS, 2050, South Africa; \\ both DST/NRF Centre of Excellence for Strong Materials, University of the Witwatersrand
}

The Al-Ru-Y system is of interest because RuAl has excellent properties for spark plugs [1] and yttrium has been used in coating Ni-based alloys [2]. Thus, the Al-Ru-Y system might provide a potential new coating material. The Al-Ru and Al-Y binary phase diagrams are well established, but the reactions in $\mathrm{Ru}-$ $\mathrm{Y}$ are more speculative, although the phases themselves are known [3]. Six phases on the $\mathrm{YRu}_{2}-\mathrm{YAl}_{2}$ transus had been reported [4]. Earlier work on the Al-Ru-Y system [5] showed mainly limited extension of the binary phases into the ternary, and located four of the phases on the $\mathrm{YRu}_{2}-\mathrm{YAl}_{2}$ transus.

Samples were made by arc-melting $99.9 \%$ pure elemental components together, using titanium as an oxygen-getter. They were then halved, mounted, and prepared for metallography. Analysis was undertaken, using elemental standards, in a JSM-840 SEM with a LINK AN10000 EDS system.

Some of the alloys had small particles of $\mathrm{Y}_{2} \mathrm{O}_{3}$, assumed to be present before or in an early stage of melting, despite taking precautions. Since these were in minor proportion, and have a very high melting point $\left(2458^{\circ} \mathrm{C}[3]\right)$, and despite the fact that they were sometimes obviously acting as nucleation sites, they were ignored in the interpretation of the microstructures. Interpreting them as (Y), which had oxidised subsequently, gave an impossible sequence of solidification reactions.

The $\mathrm{Al}_{15}: \mathrm{Ru}_{70}: \mathrm{Y}_{15}$ (at. \%) sample, which had small particles of $(\mathrm{Ru})$ and $\mathrm{RuAl}$ (with negligible $\mathrm{Al}$ ), was mostly a ternary eutectic. The ternary eutectic comprised $(\mathrm{Ru}), \mathrm{RuAl}$ and $\sim \mathrm{YRu}_{2}$ and its overall composition was $\mathrm{Al}_{14}: \mathrm{Ru}_{71}: \mathrm{Y}_{15}$.

Two phases on the $\mathrm{YRu}_{2}-\mathrm{YAl}_{2}$ transus were found in the $\mathrm{Al}_{15}: \mathrm{Ru}_{70}: \mathrm{Y}_{15}$ sample: $\sim \mathrm{Y}_{33} \mathrm{Ru}_{56} \mathrm{Al}_{11}$ and $\sim \mathrm{Y}_{33} \mathrm{Ru}_{47} \mathrm{Al}_{20}$.

The $\mathrm{Al}_{17}: \mathrm{Ru}_{39}: \mathrm{Y}_{44}$ sample had a small proportion of the oxide particles, and comprised primary $\sim \mathrm{Y}_{5} \mathrm{Ru}_{2}$ (with about 2 at. $\% \mathrm{Al}$ ). There was then a peritectic reaction forming $\sim \mathrm{Y}_{34} \mathrm{Ru}_{43} \mathrm{Al}_{23}$, and subsequently $\sim \mathrm{Y}_{34} \mathrm{Ru}_{47} \mathrm{Al}_{19}$.

The $\mathrm{Al}_{12}: \mathrm{Ru}_{11}: \mathrm{Y}_{77}$ sample comprised angular primary crystals of a ternary phase, $\sim \mathrm{Y}_{75} \mathrm{Ru}_{9} \mathrm{Al}_{16}$, surrounded by a $\sim \mathrm{Y}_{75} \mathrm{Ru}_{9} \mathrm{Al}_{16}+\mathrm{Y}_{3} \mathrm{Ru}$ eutectic, as shown in Fig. 1.

The nominal $\mathrm{Al}_{35}: \mathrm{Ru}_{42}: \mathrm{Y}_{23}$ alloy also had oxide particles. The primary phase was RuAl which was cored (but without $\mathrm{Y}$ ). The next two reactions were peritectic, forming cored $\sim \mathrm{Y}_{34} \mathrm{Ru}_{40} \mathrm{Al}_{26}$ and $\sim \mathrm{Y}_{34} \mathrm{Ru}_{33} \mathrm{Al}_{33}$. The latter two phases were also seen in the $\mathrm{Al}_{31}: \mathrm{Ru}_{33}: \mathrm{Y}_{36}$ sample, together with primary $\sim \mathrm{Y}_{50} \mathrm{Ru}_{27} \mathrm{Al}_{23}$, which is assumed to be a ternary phase.

As well as containing yttrium oxide, the $\mathrm{Al}_{39}: \mathrm{Ru}_{19}: \mathrm{Y}_{42}$ sample comprised a primary phase which lay on the $\mathrm{YRu}_{2}-\mathrm{YAl}_{2}$ transus, $\sim \mathrm{Y}_{35} \mathrm{Ru}_{22} \mathrm{Al}_{43}$, and a ternary phase, $\sim \mathrm{Y}_{68} \mathrm{Ru}_{12} \mathrm{Al}_{20}$.

The $\mathrm{Al}_{69}: \mathrm{Ru}_{14}: \mathrm{Y}_{17}$ samples had dendrites of $\sim \mathrm{RuAl}_{2}$ (with $\sim 10$ at. \% Y) surrounded by coarse needles of a 
ternary phase of composition $\sim \mathrm{Y}_{11} \mathrm{Ru}_{16} \mathrm{Al}_{73}$ with the last phase to solidify being $\mathrm{YAl}_{3}$ (Fig. 2). The ternary nature of the $\sim \mathrm{Y}_{11} \mathrm{Ru}_{16} \mathrm{Al}_{73}$ phase was confirmed by the $\mathrm{Al}_{79}: \mathrm{Ru}_{14}: \mathrm{Y}_{7}$ sample. This had primary $\sim \mathrm{Ru}_{4} \mathrm{Al}_{13}$ surrounded by $\sim \mathrm{Y}_{11} \mathrm{Ru}_{16} \mathrm{Al}_{73}$, then (Al).

The investigation of the Al-Ru-Y system revealed problems with oxidation of $\mathrm{Y}$, although the particles were small. A ternary eutectic of $(\mathrm{Ru})+\mathrm{RuAl}+\sim \mathrm{YRu}_{2}$ was found, and the congruent melting of $\mathrm{Y}_{5} \mathrm{Ru}_{2}$ was confirmed. Ternary phases of compositions $\sim \mathrm{Y}_{50} \mathrm{Ru}_{27} \mathrm{Al}_{23}$ and $\sim \mathrm{Y}_{75} \mathrm{Ru}_{9} \mathrm{Al}_{16}$, have been found, and on the $\mathrm{YRu}_{2}-\mathrm{YAl}_{2}$ transus, the phases: $\sim \mathrm{Y}_{33} \mathrm{Ru}_{56} \mathrm{Al}_{11}, \sim \mathrm{Y}_{33} \mathrm{Ru}_{47} \mathrm{Al}_{20} \sim \mathrm{Y}_{34} \mathrm{Ru}_{43} \mathrm{Al}_{23}, \sim \mathrm{Y}_{34} \mathrm{Ru}_{33} \mathrm{Al}_{33}$ and $\sim \mathrm{Y}_{35} \mathrm{Ru}_{22} \mathrm{Al}_{43}$.

\section{References}

[1] I. M. Wolf et al., Structural Intermetallics 1997, M.V. Nathal et al., eds., The Minerals, Metals and Materials Soc., Champion, 1997, p. 815.

[2] S. Grainger, ed., Engineering Coatings - Design and Application, Abington Pub., Cambridge, 1989.

[3] Ed.-in-chief T.B. Massalski, eds., H. Okamoto et al., Binary Alloy Phase Diagrams, $2^{\text {nd }}$ ed., Amer. Soc. Metals, Ohio, 1990.

[4] Eds. C. He et al., Phase Diagrams of Precious Metals Alloys, The Metallurgical Industry Press, Kunming, 1983, p. 221.

[5] L. A. Cornish and M. J. Witcomb, Proc. $15^{\text {th }}$ Int. Congress on Electron Microscopy, Microsc. Soc.

South. Afr, Onderstepoort, Vol. 1, p. 689.

[6] The assistance of Mintek, DACST and the PDI is gratefully acknowledged.
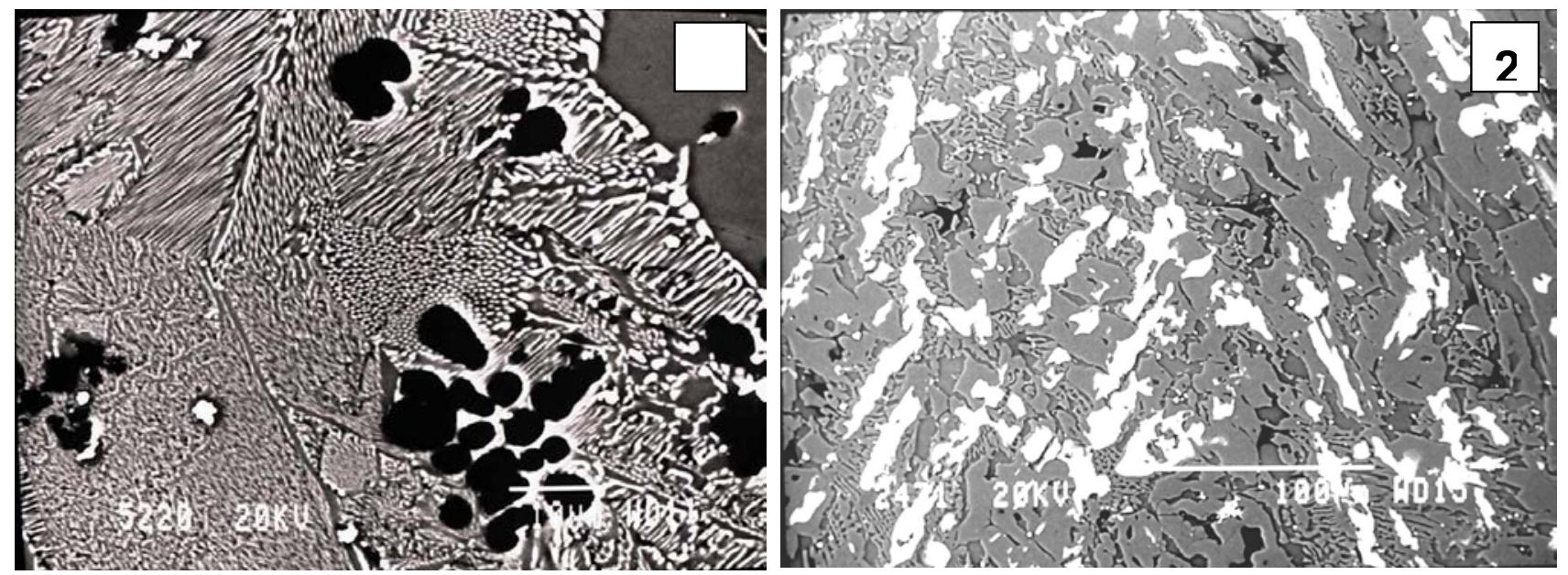

Fig. 1. Backscatter image of the $\mathrm{Al}_{12}: \mathrm{Ru}_{11}: \mathrm{Y}_{77}$ sample showing dark $\mathrm{Y}_{2} \mathrm{O}_{3}$ particles, $\sim \mathrm{Y}_{75} \mathrm{Ru}_{9} \mathrm{Al}_{16}$ (medium), in $\mathrm{a} \sim \mathrm{Y}_{75} \mathrm{Ru}_{9} \mathrm{Al}_{16}+\mathrm{Y}_{3} \mathrm{Ru}$ (light) eutectic.

Fig. 2. Backscatter image of the $\mathrm{Al}_{69}: \mathrm{Ru}_{14}: \mathrm{Y}_{17}$ sample showing $\sim \mathrm{RuAl}_{2}$ dendrites (light) with coarse needles of $\sim \mathrm{Ru}_{4} \mathrm{Al}_{13}$ (medium) and $\mathrm{YAl}_{3}$ (dark). 